\title{
Analysis on the Utilization Efficiency of Human Resources in Guangxi Based on Data Envelopment Analysis Method
}

\author{
Xin Zhu \\ Department of Management, \\ Guangxi University of Science and Technology, \\ Liuzhou, P.R.China \\ 5266736@qq.com
}

\begin{abstract}
The goal of this paper is to analyze the human resources development and utilization efficiency in the 14 cities in Guangxi. Firstly, we make an introduction about the relevant research in this field. Then, we establish the input and output index system of resources development and utilization with method of Data Envelopment Analysis. Thirdly, we make an empirical analysis on the utilization efficiency of human resources with the C2R model and DEA software. The results show human resources development and utilization efficiency and scale efficiency have positive reference value to the development of Guangxi. Finally, we put forward the strategic routes and corresponding suggestions for the development and utilization efficiency of human resources in Guangxi.
\end{abstract}

Keywords- DEA method; human resources; utilization efficiency

\section{INTRODUCTION}

Human resources play an important role as reusable and constantly value-added resources in the process of economic development and it is the key to the economic and social development. A regional social economic development level ultimately depends on the quality of human resources and the role of the play. Thus the overall quality of human resources concerns the region's economic construction success or failure. So, paying attention to human resources, comprehensive utilization and reasonable development of human resources has become a regional social and economic development strategy in the first place.

So far, many scholars domestic and international have done a lot of research for human resource use efficiency, such as Chen Jing (2004) used multi-level gray evaluation method to evaluate high technology enterprise's human resources of science and technology research and development efficiency

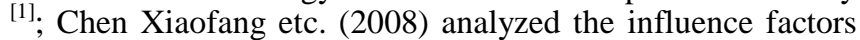
of the efficiency of enterprise human resources management systematically by the ISM model ${ }^{[2]}$; Stavrou etc. (2007) measured human resources management and enterprise business efficiency and studied results verifing the validity of the method by artificial neural networks ${ }^{[3]}$. Chou etc. (2008) used the analytic hierarchy process (AHP) to evaluate science and technology human resources competitiveness ${ }^{[4]}$. Tseng and Lee (2009) evaluated the efficiency of enterprise human

\author{
Xianjun $\mathrm{Yu}$ \\ Department of Management, \\ Guangxi University of Science and Technology, \\ Liuzhou, P.R.China \\ 411943710@qq.com
}

resources management in the framework of different enterprise culture category using the AHP/DEA ${ }^{[5]}$. Liu wenhui analyzed HanShouXian's advantages and disadvantages of human resources by the SWOT tools of public management and predicted the future demand according to human resource management is not perfect imperfect competition incentive mechanism ${ }^{[6]}$. The method qualitatively analyzed and evaluated problems often do not take this approach; Zhou Yinzhen constructed the index system of regional human resources development of the evaluation levels using analytic hierarchy process (AHP), the method could be more comprehensive, systematic to determine the various indicators, but the difficulty lied in the determination of index weight, which needed a large amount of data and be with certain subjectivity ${ }^{[7]}$; Shangdeng selected the input index and output index to evaluate the efficiency of human resources development and utilization of Xinjiang city by using the DEA method and put forward the size of the region's human resources development and utilization should be improved ${ }^{[8]}$. This method was a kind of relative efficiency evaluation, so there's no need to weigh for each data which could influence the outcome of evaluation.

As the construction process's rapid advance of the China - ASEAN free trade area, China - ASEAN expo permanently settled in Guangxi. The way of development to all kinds of advanced talents gradually transforms to export-oriented and inter-disciplinary talent, such as mastering various languages of ASEAN countries, and also being familiar with the ASEAN countries related legal and financial knowledge ${ }^{[9]}$. The senior talent with the internationalization of market analysis ability has become the goal of the foreign capital enterprise. Guangxi's economic grows rapidly, but guangxi's human resource quality level is not high. Guangxi mainly faces the talent human resources insufficiency, the imbalance in the structure of education, education funds inadequacy, underdevelopment of vocational education and higher education foundation is weak, and so on.

In the current of the knowledge economy society, in order to achiev the transformation of economic development of Guangxi, the superiority resources transformation strategy, it must strive to strengthen human resources investment, improve the efficiency of human resources development and utilization. The development and utilization of human 
resources is a series of planned activities and processes, including excavation, cultivate, configuration and using of human resources, investment, and mobilization and organization with the purpose, so that they have to adapt to the realistic production process required quality and ability, eventually achieve the reasonable combination of human resources and material resources and promote and promote the sound development of social economy.

\section{METHODOLOGY}

\section{A. The Method of Data Envelopment Analysis (dea) and $C^{2} R$ Model}

The method of Data Envelopment Analysis (DEA) is set up by Charnes and Cooper who are America operational research. The method is a Econometric approach which is modeled by linear programming theory. DEA is a kind of evaluation system based on the concept of relative efficiency evaluation ${ }^{[10]}$. It is based on the concept of relative efficiency. According to the input and output data, it's a relative effectiveness evaluation method to the same type of unit or project (decision making units). Since being put forward the method was applied in many areas and now it has become one kind of the most important analysis tool on the economic research, decision analysis, and evaluation technology.

First of all, using DEA analysis method no longer needs to determine the weight of each index weight that is preferred sense. Because the method is set out from the perspective of the most conducive to the decision making units and is studied with decision making units of input and output weights for variables. Secondly, using DEA method to evaluate the decision making unit (DMU), does not need to determine the explicit expression of the relationship of the input and output between the decision making units, and doesn't have to consider the dimensions of different indicators. The analysis method rules out many subjective factors and avoids the partial of analyzing indicators processing, not only improves the objectivity of the evaluation results, but also simplifies the problem. So it is simple and efficient to quantitative research in Guangxi human resources development and utilization efficiency problem with the DEA method. Supposing there are $\mathrm{n}$ decision making units, each decision making units $\operatorname{DMU}_{\mathrm{j}}(\mathrm{j}=1,2, \ldots, \mathrm{n})$ are $\mathrm{m}$ type of the input and $\mathrm{s}$ type of output, respectively with $X_{j}$ and $Y_{j}, X_{j}=\left(X_{j 1}, X_{j 2}, \ldots, X_{j m}\right)^{T}$, $Y_{j}=\left(Y_{j 1}, Y_{j 2}, \ldots, Y_{j s}\right)^{T}, j=1,2 \ldots, n$. The $C^{2} R$ model's dual programming of evaluating and judging the effectiveness of the $\mathrm{j}_{0}$ th decision making units is:

The value of $\theta$ varies from 0 to 1 . It is the relative efficiency of decision making units value, namely the effective use of the input relative to the output and reflects the reasonable degree of the decision-making unit degree of rational resource allocation. The greater of the $\theta$ shows the resource allocation of the decision making unit is more reasonable. Slack variable is a vector which corresponds to the input vector of slack variables and the output of surplus variable vector, $\mathrm{s}^{-}=\left(\mathrm{s}_{1}{ }^{-}, \mathrm{s}_{2}{ }^{-}, \ldots, \mathrm{s}_{\mathrm{m}}{ }^{-}\right)^{\mathrm{T}}, \mathrm{s}^{+}=\left(\mathrm{s}_{1}{ }^{+}\right.$, $\left.\mathrm{s}_{2}{ }^{+}, \ldots, \mathrm{s}_{\mathrm{s}}^{+}\right)^{\mathrm{T}}$.
Assuming that the optimal solution of linear programming is $\theta^{*}$ and $\lambda^{*}$, so three DEA validity judgment of the decision making units $\mathrm{j}_{0}$ are as follows:

( $i$ ) if $\theta^{*}=1, s^{+}=0$, and $s^{-}=0$, it is said the $\mathrm{DMU}_{0}$ is DEA effective and resources obtain the sufficient utilization in the $\mathrm{n}$ system of decision making units.

(ii ) if $\theta^{*}=1, \mathrm{~s}^{+} \neq 0$,or $\mathrm{s}^{-} \neq 0$,it is said the $\mathrm{DMU}_{0}$ is weak DEA efficient. It shows that the decision-making unit is close to a relatively optimal state, but there is still room for improvement, namely even reduce the input $\mathrm{X}_{0}$ still can keep the original output $\mathrm{Y}_{0}$ unchanged, or under the condition of invariable in input $\mathrm{X}_{0}$ can also would improve output $\mathrm{Y}_{0}$ in the $\mathrm{n}$ economic system of decision making units.

(iii) if $\theta^{*}<1$, it is said the $\mathrm{DMU}_{0}$ is DEA invalid. It shows comparing with other evaluation decision unit, the decision making unit is far from achieving the optimal state, at this point it can be combined to put down to the original input $\mathrm{X}_{0}$ of the proportion of $\theta$ and keeping the original output $\mathrm{Y}_{0}$ is not reduced in the economic system composed of $n$ decision making units.

\section{B. Index Selection and Data Collection}

The development and utilization of human resources is a complex and open system and its indicators are varied. It is considered that the availability of each indicator and internal system index factors avoid coming about the strong linear relationship, so in the research of human resources development and utilization efficiency, the input indexes are total population number $\left(\mathrm{I}_{1}\right.$, thousand), education investment $\left(\mathrm{I}_{2}\right.$, billion), the number of ordinary middle school students $\left(\mathrm{I}_{3}\right.$ thousand), and the number of health institutions $\left(\mathrm{I}_{4}\right)$. Total population number represents the foundation of human resources and development potential; A regional educational development level can well reflect the region's emphasis on human resources development and utilization degree, and then reflects the level of human resources development and utilization efficiency of the region; The number of ordinary middle school students is stands for the region's basic situation and level of human resources development; The number of health institutions reflects the human resources' status quo and development of scale in the social security and welfare benefits.

The output indicators are: the local $\operatorname{GDP}\left(\mathrm{O}_{1}\right.$, billion $)$, the number of patent applications $\left(\mathrm{O}_{2}\right.$, case $)$, urban per capita savings deposit balance at the end of the year $\left(\mathrm{O}_{3}\right.$, Yuan).The local GDP reflects the region's relationship between the human resources and the economic development; The number of patent application reflects the human resources development and utilization of achievement; Urban residents savings deposit balance at the end of the year reflects the performance of human resources development and utilization in to the next stage.

The data of paper comes from 《Statistical Yearbook of Guangxi》 published in 2012. The index data of the human resources development and utilization's input and output around Guangxi in 2011 are shown in table I: 
TABLE I. THE INDEX DATA OF THE HUMAN RESOURCES DEVELOPMENT AND UTILIZATION'S INPUT AND OUTPUT AROUND GUANGXI IN 2011

\begin{tabular}{|c|c|c|c|c|c|c|c|}
\hline Region & $\mathrm{O}_{1}$ & $\mathrm{O}_{2}$ & $\mathrm{O}_{3}$ & $\mathrm{I}_{1}$ & $\mathrm{I}_{2}$ & $\mathrm{I}_{3}$ & $\mathrm{I}_{4}$ \\
\hline Nanning & 221.151 & 2225 & 16110 & 7115 & 5.355 & 378 & 2324 \\
\hline Liuzhou & 157.972 & 1280 & 13703 & 3748 & 3.445 & 174 & 2151 \\
\hline Guilin & 132.757 & 1767 & 8334 & 5218 & 3.984 & 202 & 1661 \\
\hline Wuzhou & 73.524 & 288 & 6938 & 32764 & 2.731 & 203 & 1677 \\
\hline Beihai & 49.658 & 265 & 9090 & 16789 & 1.431 & 1026 & 440 \\
\hline Fangchenggang & 41.377 & 109 & 5910 & 9139 & 0.815 & 47 & 539 \\
\hline Qinzhou & 64.665 & 211 & 9735 & 39117 & 2.379 & 205 & 442 \\
\hline Guigang & 63.441 & 221 & 10853 & 52769 & 2.91 & 355 & 4409 \\
\hline Yulin & 101.994 & 847 & 11633 & 68484 & 4.002 & 3986 & 3122 \\
\hline Baise & 66.41 & 174 & 8306 & 38528 & 3.275 & 1843 & 2130 \\
\hline Hezhou & 35.64 & 318 & 9944 & 23325 & 1.627 & 13 & 1433 \\
\hline Hechi & 51.813 & 179 & 9666 & 40178 & 2.918 & 2058 & 564 \\
\hline Laibin & 48.621 & 148 & 15956 & 26173 & 2.121 & 126 & 124 \\
\hline Chongzuo & 49.185 & 74 & 9525 & 24657 & 2.033 & 78 & 1286 \\
\hline
\end{tabular}

\section{RESULT}

The input indicators of DEA method refers to the economic quantity of the decision making units' consumption in social economic activities, the output index refers to the economic quantity of the decision making units in a combination. So, according to the evaluation index system and the raw data of input and output in table
I, we set up the $C^{2} \mathrm{R}$ model with each district cities as decisionmaking unit and found the solution using DEA software. Each district cities' human resources development and utilization efficiency and the corresponding scale efficiency in Guangxi can be analyzed (as shown in Table II).

TABLE II. THE OUTPUT RESULT OF DEA MODEL

\begin{tabular}{|c|c|c|c|c|c|c|c|c|}
\hline \multirow{2}{*}{ Region } & \multirow{2}{|c|}{$\theta^{*}$} & \multicolumn{7}{|c|}{ Slack Variable } \\
\hline Nanning & 1 & 0 & 0 & 0 & 0 & 0 & 0 & 0 \\
\hline Liuzhou & 1 & 0 & 0 & 0 & 0 & 0 & 0 & 0 \\
\hline Guilin & 1 & 0 & 0 & 0 & 0 & 0 & 0 & 0 \\
\hline Wuzhou & 0.552 & 0 & 155.594 & 1052.038 & 10.519 & 0 & 2.872 & 0 \\
\hline Beihai & 1 & 0 & 0 & 0 & 0 & 0 & 0 & 0 \\
\hline Fangchenggang & 1 & 0 & 0 & 0 & 0 & 0 & 0 & 0 \\
\hline Qinzhou & 0.932 & 0 & 159.331 & 4317.748 & 89.027 & 0 & 4.913 & 0 \\
\hline Guigang & 0.525 & 0 & 97.352 & 0 & 112.773 & 0 & 11.387 & 1959.629 \\
\hline Yulin & 0.640 & 101.168 & 0 & 0 & 155.646 & 0 & 11.459 & 571.31 \\
\hline Baise & 0.408 & 0 & 183.863 & 0 & 8.685 & 0 & 0.286 & 107.331 \\
\hline Hezhou & 0.968 & 206.227 & 0 & 0 & 42.736 & 0 & 1.99 & 900.811 \\
\hline Hechi & 0.601 & 0 & 68.444 & 2283.9 & 29.563 & 0 & 0.848 & 0 \\
\hline Laibin & 1 & 0 & 0 & 0 & 0 & 0 & 0 & 0 \\
\hline Chongzuo & 1 & 0 & 0 & 0 & 0 & 0 & 0 & 0 \\
\hline
\end{tabular}




\section{According to the above output, it can be seen:}

First, human resources development and utilization efficiency of the gap of each city in Guangxi is bigger and it is closely related to the regional economic development level. It can be found that the regions' whose economic development is faster and better DEA efficient data is higher, such as Nanning, Liuzhou, and Beihai. About half of the 14 cities, the $\theta^{*}$ don't to 1 and their DEA are invalid, It accounts for the human resources development and utilization efficiency of half cities in Guangxi does not reach the best state, the ratio of inputoutput is imbalance and needs to further efforts to improve the efficiency of resource allocation.

Second, though Beihai, Fangchenggang, Laibin and Chongzuo's input or output are not of the highest and even lower than Wuzhou, Qinzhou and other regions, those human resources development and utilization efficiency is higher. At the time of DEA efficiency analysis, it needs to focus on the balance between the elements rather than the absolute number.

Third, in the input index, the level of education investment efficiency is highest in 14 cities of Guangxi and it followed by health care institutions. It suggests that the fundamental education investment and the medical and health care is got the guarantee in distributing the input of human resources.

Fourth, the number of patent application and residents savings slack variable data are bigger in the output index, it reflects that there is still half prefectures' inputs are not take full advantage, that is, it can be produced a certain amount of patent application and the residents' savings under the condition of not changing the number of inputs.

\section{CONCLUSION}

From above, it can be found 7 cities in Guangxi are not DEA efficient, but each city is different and its absolute number is not the same when DEA is invalid induced by the same factors. It means that it should be suit to the case when they are put forward policy suggestions and human resources development and utilization of structure and system should be adjust gradually. Here, for the condition of the overall utilization of human resources in this district, some suggestions are put forward as follows:

First of all, the key is the weak links should be strengthened. In terms of various indicators of actual investment, the input of factors of human resource development in Guangxi is still insufficient compared with the national level, especially in the basic education and health care so it is established demonstration effect for human resources development input source. Although the development and utilization efficiency of human resources are not identical specific to different city of Guangxi, its natural resources tend to be very rich in the economic underdeveloped regions. In the trend of the optimal allocation of market resources and regional productivity layout reasonable, it must be established some key projects in which many talent resources comes in in the economic underdeveloped regions.

Secondly, ideas must be changed to develop and utilize human resources. It is important to enhance the concept of commodity of the masses, the competitive consciousness, the consciousness of time and efficiency and innovation spirit, etc through various channels and ways. It should be fully play to plan the human resource development plans by the role of government. The government department should set up the concept that human resources are the first resource of the economic development, education, health, publicity, cultural departments and the news media units should set up projects and advertise regularly.

Lastly, it needs to strengthen the construction of highlevel talent team. Relying on the project to attract talents; It is encouraged that talent with capital, technology and project settle in Guangxi; Regular exchange of personnel should be held to provide a platform for talent two-way choice; To participate in domestic large job fairs draw into high-level talents.

\section{REFERENCES}

[1] Chen Jing Han Botang, Yu Lijuan. Multilevel grey evaluation method in the application of high-tech enterprise human resources of science and technology evaluation $[\mathrm{J}]$. Science and technology management research 2004 (3) : 100-102.

[2] Chen Xiaofang Wang Jianjun. ISM application in improving the efficiency of enterprise human resource management [J]. Journal of management informationization in China, 2008, 11 (17) : 91-94.

[3] Eleni T. Stavrou, Christakis Charalambous, Stelios Spiliotis.Human Resource Management and Performance:A Neural Network Analysis[J]. European Journal of Operational Research, 2007, 181(1): 453-467.

[4] Chou Yingchy,i Hsu Yingying,YenHsiny.Human Resources for Science and Technology: Analyzing Competitiveness Using the Analytic Hierarchy process[J]. Technology in Society, 2008, 30(2): 141-153.

[5] TsengYafen,Lee Tzaizang.Comparing appropriate Decision Support of Human Resource Practices on Organizational Performance with DEA/AHP Model[J]. Expert Systems with Applications, 2009, 36(3):6548-6558.

[6] MarkA.Huselid, Susan E. Jackson,Randall S.Schuler.Technical and Strategic Human Resource Management Effectiveness as Determinants of Firm Performance[ J]. Academy of Management,1997, 40(1): 171188

[7] Y. Wang,Y. Luo, DEA efficiency assessment using ideal and anti-ideal decision making units, Applied Mathematics and Computation 173 (2) (2006) $902-915$.

[8] D. Wu, Z. Yang, L. Liang, Efficiency analysis of cross-region bank branches using fuzzy data envelopment analysis. Applied Mathematics and Computation, in press, doi:10.1016/j.amc.2006.01.037.

[9] N.K. Avkiran, H. Morita, Predicting Japanese bank stock performance with a composite relative efficiency metric: a new investment tool, Pacific-Basin Financ. J. 18 (2010) 254-271.

[10] C. Kao, S.-N. Hwang, Efficiency measurement for network systems: IT impact on firm performance, Decis. Support. Syst , 2010, $48437-446$. 